\title{
Evaluating the L-MEB model from long term microwave measurements over a rough field, SMOSREX 2006
}

\author{
Arnaud Mialon, Jean-Pierre Wigneron, Senior Member 03, IEEE, Patricia de Rosnay, Maria \\ Jose Escorihuela, Yann H. Kerr, Member 88, Senior Member 01, IEEE
}

\begin{abstract}
The present study analyses the effectso of the roughness on the surface emission at L-band based on observations acquired during a long term experiment. At the SMOSREX (Surface Monitoring Of the Soil Reservoir EXperiment) site near Toulouse, France, a bare soil was ploughed and monitored over more than a year by means of a $L$-band radiometer, profile soil moisture and temperature sensors as well as a local weather station, accompanied by 12 roughness campaigns. The aim of this study is (1) to present this unique database, and (2) to use this dataset ${ }^{8}$ to investigate the semi-empirical parameters for the roughness in L-MEB (L-Band Microwave Emissiono of the Biosphere), that is the forward model used, in the SMOS (Soil Moisture and Ocean Salinity) soil moisture retrieval algorithm. In particular, we studied the link between these semi empirical parameter $5^{53}$ and the soil roughness characteristics expressed in ${ }^{4}$ terms of standard deviation of surface height $(\sigma)$ and 5 the correlation length (LC). The dataset verifies that ${ }_{6}$ roughness effects decrease the sensitivity of surface emission to soil moisture, an effect which is most pronounced at high incidence angles and soil moisturé and at horizontal polarization. Contradictory to pre $^{59}$ vious studies, the semi-empirical parameter $Q r$ waso not found to be equal to 0 for rough conditions. $A_{1}$ linear relationship between the semi-empirical parameters $\mathbf{N}$ and $\sigma$ was established, while $\mathbf{N}_{H}$ and $\mathbf{N}_{V}^{62}$ appeared to be lower for a rough $\left(\mathrm{N}_{H} \sim 0.59\right.$ and $^{3}$ $\mathbf{N}_{V} \sim \mathbf{- 0 . 3 )}$ than for a quasi-smooth surface. This ${ }^{4}$ study reveals the complexity of roughness effects and demonstrates the great value of a sound long-term dataset of rough L-band surface emissions to improve our understanding on the matter.
\end{abstract}

Index Terms-SMOS, Roughness, Passive $\mathrm{Mi}_{\overline{6}}$ crowave, L-band, L-MEB model.

\section{INTRODUCTION}

$\mathbf{S}$ OIL moisture is a key parameter controlling ${ }^{3}$ air-land interface exchanges. Although very ${ }^{74}$

A.Mialon and Y.Kerr are with the Centre d'Etudes Spatiales6 de la Biosphère (CESBIO), Toulouse Cedex 4, France.

P. de Rosnay is also with the CESBIO and presently at the European Centre for Medium-Range Weather Forecast ${ }^{8}$ (ECMWF), Reading, UK).

J.P. Wigneron is with the Institut National de Recherche Agronomique (INRA), Bordeaux, France.

M.J Escorihuela is with isardSAT - Earth Observation ${ }^{1}$ Applications- Barcelona. important in many applications (climate models, agriculture, water resources management), it is difficult to monitor this variable at a global scale. The SMOS (Soil Moisture and Ocean Salinity) satellite mission $[1 ; 2]$, successfully launched in November 2009, is the first mission to deliver global surface soil moisture fields at a high temporal resolution of 3 days. The retrieval scheme to derive soil moisture [3] is based on multi-angular passive microwave brightness temperatures $(\mathrm{f}=1.4 \mathrm{GHz}$ ) as measured by the instrument [4] and on surface emission models at L-band (L-MEB, L-band Microwave Emission of the Biosphere $[5 ; 6 ; 7])$.

Land surface emission at this wavelength is mainly controlled by soil moisture but important issues are still to be tackled [8] such as roughness, which is the focus of this paper. Roughness influence on surface emission is complex as it implies 3-D geometric soil surface features as well as soil moisture heterogeneity, in particular between peaks and hollows. Its major effect is to decrease the sensitivity of L-band brightness temperatures to soil moisture [9;10]. Shi et al. [11] found by the use of an Integral Equation Model (IEM) that roughness influence is more significant at high incidence angles and high soil moisture content as well as a function of polarization. They noted an increase in emissivity with roughness at the horizontal polarization at low incidence angles. For dry soil, the emissivity of the vertical polarization (typically higher than $\sim 0.8$ ) shows a decrease compared with that of a flat surface, whereas for wet soil (emissivity lower than $\sim 0.8$ ) an increase is observed.

Using complex models as the IEM approach to compute the surface emissivity is not possible in the SMOS soil moisture algorithm as it needs many inputs and its computation is time demanding. Instead the SMOS level2 retrieval algorithm [3] uses semi-empirical approaches [7;8] to compute the emission of the surface. The correction for a rough surface $[9 ; 10 ; 12 ; 13]$ 
is based on empirical parameters $\left(\mathrm{Hr}, \mathrm{N}_{V}, \mathrm{~N}_{H^{37}}\right.$ Qr) that have to be calibrated with in-situ datas reflecting local surface characteristics (soil texture 39 level of roughness). Most recent studies on $\mathrm{L}_{* 0}$ band emission $[14 ; 15 ; 16]$ have retrieved these parameters to best fit the observations, but more investigations are needed on roughness to relate the $e_{3}$ soil L-MEB parameters to the surface roughnes\$4 characteristics.

The roughness analyses conducted so far have aldo been either restricted to short investigation periods $[17 ; 13]$ or to almost flat surface conditions $[18]_{8}$ only. These have motivated the present study whicho for the first time focuses on a rough soil observedo over a long time period at the SMOSREX (Surface Monitoring Of the Soil Reservoir EXperiment) siter in 2006/07. A bare soil was ploughed creating a very rough surface and its roughness evolved for over more than a year naturally due to climatics events (rainfalls, wind).

The aim of this study is twofold. First, thiss unique database (referred to as SMOSREX-2006) is presented and the L-band observations overo the rough surface covering a wide range of soid moisture conditions (from very wet to very dry) arez analysed over a long period of time (14 months) Second, the SMOSREX-2006 is used to evaluater the roughness parameters of the semi empiricads model used in the L-MEB model. Qr, $\mathrm{Hr}$ and $\mathrm{N}_{1 \beta^{6}}$ ( $p$ for the polarization horizontal or vertical) arez retrieved in this evaluation and compared with thes surface roughness characteristics.

\section{MATERIAL}

\section{A. Database and experimental site}

In preparation of the SMOS mission, the experimental site of SMOSREX (Surfaces Monitoring Of the Soil Reservoir EXperiment [19]) has been set up near Toulouse in the Southwest6 of France. Operating since 2003, the database hasz been used to improve the models implemented ins the SMOS soil moisture retrieval $[3 ; 20 ; 18] . \quad 179$ It is equipped with the LEWIS (L-band radiometero for Estimating Water in Soil) radiometer [21, which has been continuously monitoring the emission of the surface. The instrument, placeds on a $15 \mathrm{~m}$ high tower can monitor two fieldss4 one with grasscover and a bare soil. It acquiress brightness temperatures at vertical and horizontad polarizations (commonly referred to as $\mathrm{V}$ and $\mathrm{H}$ के at the same frequency as SMOS, i.e. $1.4 \mathrm{GHz}$, ats several incidence angles (i.e. 20, 30, 40, 50 and $60^{\circ}$ ) every 3 hours (i.e. $2 \mathrm{~h} 30,5 \mathrm{~h} 30,8 \mathrm{~h} 30,11 \mathrm{~h} 3 \mathrm{O}_{30}$ 14h30, 17h30, 20h30, 23h30 UTC).

Additionally, ground measurements are available. Soil texture was analysed and the bare soil was found to be $17 \%$ clay, $36 \%$ sand and $47 \%$ silt [19]. The SMOSREX site is equipped with a weather station, which has been monitoring meteorological data (air temperature, pressure, precipitation, wind) and soil moisture and temperature profiles are measured on each field every 30 minutes. Temperatures measured at different depths, i.e. at $1 \mathrm{~cm}, 5 \mathrm{~cm}, 20 \mathrm{~cm}, 50 \mathrm{~cm}$ and $90 \mathrm{~cm}$ with one probe per depth, at the same location as the soil moisture probes, are used to compute the soil temperature. Surface soil moisture is obtained by averaging data from 5 probes placed at the surface (top 0-6 $\mathrm{cm}$ layer) on the bare soil field. Soil moisture probes are calibrated from gravimetric measurements [22], from which soil density is estimated.

It is important to note that obtaining an accurate estimation of soil moisture is difficult and can be slightly different from what contributes to the brightness temperatures measured by the radiometer. Due to surface heterogeneity, some differences can occur between the surface covered by the probes $\left(\sim 4 \mathrm{~m}^{2}\right)$ and LEWIS field of view that covers a wider surface [19]. Moreover, peaks and hollows imply strong heterogeneity in the surface soil moisture conditions, as soil water content is generally higher in hollows than on peaks. Finally, soil moisture probes measure the dielectric constant over the $0-6 \mathrm{~cm}$ top soil layer, whereas the surface emission in L-band is expected to be correlated to the soil moisture of the top 2-3 $\mathrm{cm}$ soil layer [23].

\section{B. Roughness measurements}

The roughness experiment took place on the bare soil field. On January 13th, 2006 the field was ploughed in a deep manner to ensure a distinct row structure parallel to LEWIS plane of incidence. Thereafter, surface roughness changed naturally over time in response to climatic events, mainly rainfalls and wind.

Surface roughness is measured by means of a two meter long needle board with 201 needles at $1 \mathrm{~cm}$ spacing. The needles move freely in the vertical direction and were allowed to fall til they touched the surface reproducing surface variations. Twelve measurement campaigns were conducted over the following 14 months (see Table I), each consisting in the acquisition of several roughness profiles (up to 6), in both directions, i.e. parallel and perpendicular to the plane of incidence of 
the LEWIS instrument. Pictures of each vertical profiles were taken with a digital camera to obtainz the corresponding numerical profiles of the height variation. These were then used to derive two statis ${ }_{44}$ tical parameters describing the surface, the standards deviation of heights $-\sigma$ - and the correlation lengtha -LC [24]. The daily $\sigma$ are obtained by averaging the variance, i.e. $\sigma^{2}$, of the different samples acquireds in both directions. LC was derived from the auta*9 correlation function $\mathrm{C}(\mathrm{x})$, Eq. 1 [24; 25], whicho measures the correlation between two heights seps1 arated by a distance $\mathrm{x}$ :

$$
C(x)=\frac{\sum_{i=1}^{N+1-j} z_{i} \cdot z_{j+1-i}}{\sum_{i=1}^{N} z_{i}^{2}}
$$

where $z(i)$ is the height of the needles; $j$ aаm integer $\geq 1$; the spatial displacement $\mathrm{x}=(\mathrm{j}-1) . \delta \mathrm{x} ; \delta x_{8}$ being the distance between 2 needles, i.e. $1 \mathrm{~cm}$; 9 the number of needles $\mathrm{N}=201$. The $\mathrm{LC}$ correspondso to the distance $\mathrm{x}$ where the correlation functiona (Eq. 1) has decreased to 1/e, i.e. beyond which two heights are no longer statistically correlated $d_{2}$ [24]. The auto-correlation function is commonly approximated by the function $\left.\mathrm{C}(\mathrm{x})=\exp \frac{\left(-|x|^{2}\right.}{L C^{n}}\right)_{62}$ where $\mathrm{n}=1$ for the Exponential model or $\mathrm{n}=2$ for the Gaussian model [26; 25; 27]. For each day of measurement LC is simply the average of the different profiles, mixing both directions. For example, a flat surface is characterized by a low $\sigma_{269}$ and a high LC.

Data acquired before this campaign, i.e. in February and April 2004 [18] and in January 13th just before ploughing the soil, are also used as they provide additionnal information concerning a quasi-smooth surface. Roughness was also measured in 2010 s2 that the soil roughness temporal variation could $b_{276}^{275}$ estimated at interannual scale.

\section{Methodology}

\section{A. Observations}

The first part of our study is dedicated to surfaces emission at L-band as observed by the LEWIS。 radiometer. All cases such as freezing, snow (snow storm on January 28-30 2006) that may introduce 2 artefacts are excluded from the dataset. It is mores pertinent to study surface emissivity than brightness 4 temperature as the latter is also influenced by thes soil temperature. The emissivity $\varepsilon$ of a bare soido is obtained from the measured brightness tempera 87 tures by removing surface temperature and the skxs contributions by applying the following $\varepsilon_{p}=\left(\mathrm{TB}_{\beta \gamma 9}\right.$ $\left.-\mathrm{TB}_{s k y}\right) /\left(\right.$ Teff $-\mathrm{TB}_{s k y}$ ), where the subscript po stands for the polarization ( $\mathrm{H}$ or $\mathrm{V})$, and Teff is 1 the effective soil temperature [28] as computed from measured temperatures at all depths based on $[19 ; 29]$. The sky contribution $\mathrm{T}_{s k y}$ is quite low at $\mathrm{L}-$ band and set to a constant value of $3.7 \mathrm{~K}$ according to $[21 ; 30]$.

To study the effect of surface roughness on the measured signal, the prevailing surface conditions are divided into four classes of differing $\sigma$. Ranges of $\sigma$ are defined from a trend of measured $\sigma$ (Eq. 5) to better emphasize the effect of roughness on the signal. The evolution of $\sigma$ with time (Table I and Fig. 1) suggests the following ranges : $\sigma<16 \mathrm{~mm}$ relative to smooth surface, i.e. before the campaign ; $\sigma$ belonging to the range $16-20 \mathrm{~mm}$ characterizing the steady state reached by the surface at the end of the campaign, from the end of April 2006 to March 2007 ; $\sigma$ between 20 and $24 \mathrm{~mm}$ for the transition between very rough and steady state surface, from February to April 2006 ; and a last case concerning a very rough surface characterized by a $\sigma$ higher than $24 \mathrm{~mm}$, just after ploughing.

\section{B. Surface modeling}

This database is also used to retrieve and study the semi-empirical parameters in the L-MEB that account for the effect of a rough surface [3;7]. The emission of a flat surface is obtained by computing its dielectric constant from soil conditions, i.e. texture, temperature and surface soil moisture. The model developed by Mironov et al. [31; 32] is used as it has been shown to be more relevant for our experiment site [23] than the Dobson's model [33; 34]. The reflectivity $\Gamma=1-\varepsilon$, is then derived using Fresnel's law for a flat soil. The surface emission, or reflectivity, must then be corrected to take into account a rough air-soil interface. This roughness contribution is estimated by the following semi-empirical approach $[10 ; 17 ; 18]$ :

$$
\Gamma_{p}(\theta)=\left[(1-Q r) \cdot \Gamma_{p}^{o}(\theta)+Q r \cdot \Gamma_{q}^{o}(\theta)\right] \cdot e^{-H r \cdot \cos ^{N} p(\theta)}
$$

where $\Gamma$ is the reflectivity with the subscripts $p$ and $\mathrm{q}=\mathrm{V}$ or $\mathrm{H}$ for the Horizontal and Vertical polarizations; the index 0 stands for reflectivity of a flat surface computed from the Fresnel's law; $\theta$ being the incidence angle; $\mathrm{Qr}, \mathrm{Hr}, \mathrm{N}_{p}$ are the roughness parameters to be calibrated $[10 ; 17]$. Qr is a mixing factor that allows us to take into account the polarization mixing caused by the rough surface, $\mathrm{N}_{p}$ allows us to account for the incidence angle [35] and depends on the polarisation [18] and $\mathrm{Hr}$ is the effective roughness parameter. 
A first attempt to relate these empirical parameters to surface roughness suggested that 2 $\mathrm{Hr}=(2 k \sigma)^{2}$ [9]. Hr was also found to depend $\mathrm{d}_{3}$ on soil moisture $[17 ; 18 ; 14]$ but as it has nota been confirmed [23], it is not considered in thes present study. This dependence could be partiallyta explained by a mismatch between sampling deptha of soil moisture sensors and the actual deptho of the surface emission layer in L-band [23 $]_{49}$ $\mathrm{N}_{p} \quad(\mathrm{p}=\mathrm{H}$ or $\mathrm{V}$ for horizontal and vertical 0 polarization) was found to be different for the twor polarizations and $\mathrm{N}_{H}=1$ and $\mathrm{N}_{V}=-1$ were found for our SMOSREX site [18]. Qr is generally considered to be negligible $[14 ; 15 ; 13 ; 18]$ at L-band but in reality a rough surface implies खa mixing in polarization $[10 ; 26]$ that can only bet simulated by setting $\mathrm{Qr}>0$ [11].

\section{Parameter retrieval:}

4 parameters are unknown in Eq. 2, that are Qr, $\mathrm{H}_{3 ̧}$ $\mathrm{N}_{H}$ and $\mathrm{N}_{V}$. The retrieval is done in two steps. Theg first one is based on a relationship between $\mathrm{N}_{\not Y 0}$ and $\mathrm{N}_{V}$ [18]. Indeed, both theory using Fresnel 3 law and observations over a flat surface show that 2 the reflectivity at $\mathrm{H}$ and $\mathrm{V}$ polarizations are related 3 by the following approximate equation (see [18])364

$$
\Gamma_{H}(\theta)=\left[\Gamma_{V}(\theta)\right]^{\cos ^{\Delta N}(\theta)}
$$

For a smooth surface, $\Delta \mathrm{N}$ (Eq. 3), i.e. the difference $\left(\mathrm{N}_{H}-\mathrm{N}_{V}\right)$, was found to be equal $t_{\beta_{8}}$ 2 [18] which is not relevant for a rough surfaces [11]. $\Gamma_{H}(\theta)$ and $\Gamma_{V}(\theta)$ are extracted from ougro database (i.e. LEWIS measurements) for each day $y_{1}$ of the roughness campaign (see Table I, left hand $\phi_{2}$ column) allowing us to compute $\Delta N$ for rough ${ }_{3}$ conditions. The second step uses Eq. 2 from Lewis $\$_{4}$ brightness temperatures, where $\mathrm{N}_{H}-\mathrm{N}_{V}$ are linke, ${ }_{5}$ together as a results of the first step.

The retrieval consists of minimizing a cost function that computes the quadratic differences between $z_{8}$ measured emissivities $\left(\varepsilon_{\text {lewis }}\right.$ at incidence angles $s_{9}$ of $\theta=20,30,40,50^{\circ}$ and both polarizations 8 and simulated emissivities $\left(\varepsilon_{\text {model }}\right)$. This sets the best values of parameters (Eq. 2) that fit thes observations [3] [5]. The cost function to bes minimized is:

$$
C F=\frac{\sum\left(\varepsilon_{\text {lewis }}-\varepsilon_{\text {model }}\right)^{2}}{\delta\left(\varepsilon_{\text {lewis }}\right)^{2}}+\sum_{i} \frac{\sum\left(P_{i}^{\text {init }}-P_{i}\right)^{2}}{\delta\left(P_{i}^{2}\right)}
$$

where $\varepsilon_{\text {lewis }}$ at all angles and polarizationso are used; $\delta\left(\varepsilon_{\text {lewis }}\right)$ being the error in emissivitłox measured by LEWIS instrument [21]; $\mathrm{P}_{i}$ are the retrieved parameters $\left(\mathrm{Qr}, \mathrm{Hr}\right.$, and $\mathrm{N}_{p}$ ), $\mathrm{P}_{i}^{\text {init }}$ the initial values of the retrieved parameters $\left(\right.$ respectively $\mathrm{Qr}^{\text {init }}=0.1, \mathrm{Hr}^{\text {init }}=0.75, \mathrm{~N}_{p}^{\text {init }}=1$ ); and $\delta\left(P_{i}\right)$ the standard deviation of the retrieved parameters $\left(\delta \mathrm{Qr}=1, \delta \mathrm{Hr}=2, \delta \mathrm{N}_{H}=1\right)$.

As Qr was found to be $=0$ [13], two cases are considered here: A) where $\mathrm{Qr}=0$ and $\mathrm{Hr}, \mathrm{N}_{H}$ and $\mathrm{N}_{V}$ are retrieved and B) all the 4 parameters Qr, $\mathrm{Hr}, \mathrm{N}_{H}$ and $\mathrm{N}_{V}$ are retrieved.

\section{Results AND Discussion}

This section presents the results obtained from the SMOSREX-2006 campaign. Firstly, roughness measurements are presented for 14 months and secondly, the emissivities measured by the LEWIS instrument are analyzed to better understand the effect of roughness on the L-band surface emission. Finally, this database is used to study the semi empirical model that accounts for roughness in L-MEB. The parameters of the semi-empirical model are derived and related to surface roughness conditions.

\section{A. Measured roughness}

Table I presents the means and standard deviations of $\sigma$ and LC as well as the ratio $\sigma / \mathrm{LC}$ acquired during each day of the campaign. Mean values are obtained considering samples at both orientations, i.e. parallel and perpendicular to LEWIS plane of incidence. Before ploughing, the surface was almost flat characterized by $\sigma=4.73 \pm 1.31 \mathrm{~mm}$ and a correlation length $\mathrm{LC}=$ $94.11 \pm 38.81 \mathrm{~mm}$. As a comparison, previous measurements of the SMOSREX site [18] reported $\sigma=11.09 \mathrm{~mm}$ in February 2004 and $\sigma=9.12 \mathrm{~mm}$ in April 2004, indicating a smooth surface. After ploughing, the surface was characterized by a standard deviation height $\sigma$ of $34.58 \mathrm{~mm} \pm 10.29$ $\mathrm{mm}$ and a correlation length of $62.42 \pm 26.68 \mathrm{~mm}$. The auto-correlation functions (Eq. 1) suggest that the surface is closer to an exponential one than a gaussian one [26;27].

The time variations of $\sigma$ (top panel), the correlation length ( $2^{\text {nd }}$ panel from the top), the soil moisture ( $3^{\text {rd }}$ panel from the top) from the end of 2005 to March 2007 and the emissivity monitored at an incidence angle of 40 at both polarizations (bottom panel) are given in Fig. 1. The effects of the soil ploughing can be clearly distinguished on January $13^{\text {th }}$ (top panel) and is characterized 
TABLE I

STANDARD DEVIATION OF HEIGHTS, $\sigma$, AND THE CORRELATION LENGTH, LC, FOR EACH DAY OF THE CAMPAIGN. $\sigma$ AND LC ARE AVERAGED FROM EVERY SAMPLES ACQUIRED AT BOTH DIRECTIONS. THE RIGHT-HAND COLUMN IS THE RATIO $\sigma /$ LC

\begin{tabular}{lccc}
\hline $\begin{array}{l}\text { date } \\
\text { Year } \\
\mathrm{mm} / \mathrm{dd} / \mathrm{yy}\end{array}$ & $\begin{array}{c}\text { Roughness } \\
\text { Standard Deviation } \\
\text { of surface height } \sigma(\mathrm{mm})\end{array}$ & $\begin{array}{c}\text { correlation length } \\
\text { LC }(\mathrm{mm})\end{array}$ & $\begin{array}{c}\sigma / \mathrm{LC} \\
(\mathrm{mm})\end{array}$ \\
\hline $02-07-03^{*}$ & $11.51^{*} \pm 2.72$ & $59.56^{*} \pm 35.90$ & $0.19^{*}$ \\
$02-04-04^{*}$ & $11.09^{*} \pm 3.59$ & $101.22^{*} \pm 42.20$ & $0.11^{*}$ \\
$04-02-04^{*}$ & $9.12^{*} \pm 2.18$ & $70.67^{*} \pm 33.70$ & $0.13^{*}$ \\
$01-13-06^{*}$ & $4.73^{*} \pm 1.31$ & $94.11^{*} \pm 38.81$ & $0.05^{*}$ \\
$01-13-06$ & $34.58 \pm 10.29$ & $62.42 \pm 26.68$ & 0.55 \\
$01-20-06$ & $29.67 \pm 9.66$ & $70.21 \pm 29.55$ & 0.42 \\
$02-01-06$ & $26.85 \pm 11.17$ & $60.99 \pm 16.90$ & 0.44 \\
$02-20-06$ & $25.58 \pm 5.86$ & $65.26 \pm 22.88$ & 0.39 \\
$03-16-06$ & $23.10 \pm 6.61$ & $76.06 \pm 33.78$ & 0.30 \\
$04-03-06$ & $25.44 \pm 6.76$ & $87.78 \pm 34.97$ & 0.29 \\
$05-04-06$ & $20.93 \pm 7.05$ & $96.08 \pm 56.66$ & 0.22 \\
$05-30-06$ & $20.32 \pm 7.22$ & $82.39 \pm 31.60$ & 0.25 \\
$06-29-06$ & $18.05 \pm 4.84$ & $105.19 \pm 43.16$ & 0.17 \\
$11-24-06$ & $19.25 \pm 5.99$ & $118.21 \pm 33.12$ & 0.16 \\
03-12-07 & $17.43 \pm 5.72$ & $115.32 \pm 42.66$ & 0.15 \\
$10-06-10$ & $12.31 \pm 3.19$ & $122.68 \pm 62.42$ & 0.10 \\
\hline Measurements before ploughing & &
\end{tabular}

by a sharp increase in $\sigma$ followed by a notice 24 able decrease in $\sigma$ from January to May. Then $\sigma_{5}$ decreases more slowly, reaching a quasi-constanto value by July 2006. After 14 months $\sigma$ was aboutz $17.4 \mathrm{~mm}$. In June 2010 the soil roughness was mea $a_{z 8}$ sured (Table I) and presented a level of roughnesso comparable with the value measured in April 200430 as $\sigma=12.31 \pm 3.19 \mathrm{~mm}$ and $\mathrm{LC}=122.68 \pm 62.42 \mathrm{~mm}_{31}$ This trend is well reproduced using an exponential fit function (dashed line top panel Fig. 1) as:

$$
\sigma=38.35 x D O E^{-0.126}
$$

with DOE being the Day of the Experiment (dashed line top panel Fig. 1). The correlation length ${ }^{437}$ LC- presents an opposite behaviour, showing a low value after ploughing and increasing with time as the surface becomes less and less rough. A fit function was used to represent its trend (dashed line, 2nd panel from top Fig. 1) and is defined as:0

$$
L C=48.67 x D O E^{0.132}
$$

The effect of ploughing leads to a decrease ina soil moisture as shown in Fig. 1 ( $2^{\text {nd }}$ Fig. fromas the bottom) in January 2006. This effect could be explained by a redistribution of the water content 7 within the soil. Consequently, the emissivitys (bottom panel of Fig. 1) increases whereas the difference of polarization, $\varepsilon_{V}-\varepsilon_{H}$, decreases. Ito should be noted that ploughing changes also the bulk density: the soil density decreasing froma $1.5 \mathrm{~kg} / \mathrm{m}^{3}$ in 2005 , to $1.39 \mathrm{~kg} / \mathrm{m}^{3}$ in Februar $\$ 3$ 20th, 2006. Weather conditions then compact the surface, decreasing $\sigma$ and increasing the density tos $1.57 \mathrm{~kg} / \mathrm{m}^{3}$ in November 2006. Thus, ploughingo the surface modifies the soil properties (bulks density, soil moisture redistribution) impacting the dielectric constant and so the surface emissivity [17].

$\sigma$ and LC are correlated as seen in Fig. 2, which reports the relation existing between $\mathrm{LC}, \sigma / \mathrm{LC}$ and $\sigma^{2} / \mathrm{LC}$ as a function of $\sigma$. Estimating $\mathrm{LC}$ from field measurements is difficult (i.e. the measurements are noisy) but a modeling study [36] has shown that it has a very low influence on brightness temperature, especially at $\mathrm{H}$ polarization. The results of $\sigma$ and LC are slightly different to what was obtained with the same database [26] as their methodology to compute $\sigma$ and LC is different.

\section{B. Observations of surface emissivities}

Fig. 3 presents the emissivity calculated from LEWIS measurements as a function of soil moisture at 4 incidence angles, from $\theta=20^{\circ}$ (top row) to $\theta=50^{\circ}$ (bottom row) and for both polarizations ( $\mathrm{V}$ black dots and $\mathrm{H}$ grey dots). The different columns correspond to the four roughness classes from quasi-smooth on the right to rough surfaces on the left. Emissivity computed from Fresnel's law is plotted (grey and black lines Fig. 3) characterizing the emission of a perfectly smooth surface with identical surface conditions (i.e. with the same soil moisture, density, temperatures). As expected, emissivity decreases with increasing soil moisture at both polarizations and all angles. The effect of roughness is to decrease the sensitivity of surface emission to soil moisture. This can be observed especially at wet conditions (i.e. $>0.25 \mathrm{~m}^{3} / \mathrm{m}^{3}$ ), where the emissivity increases with roughness. The 

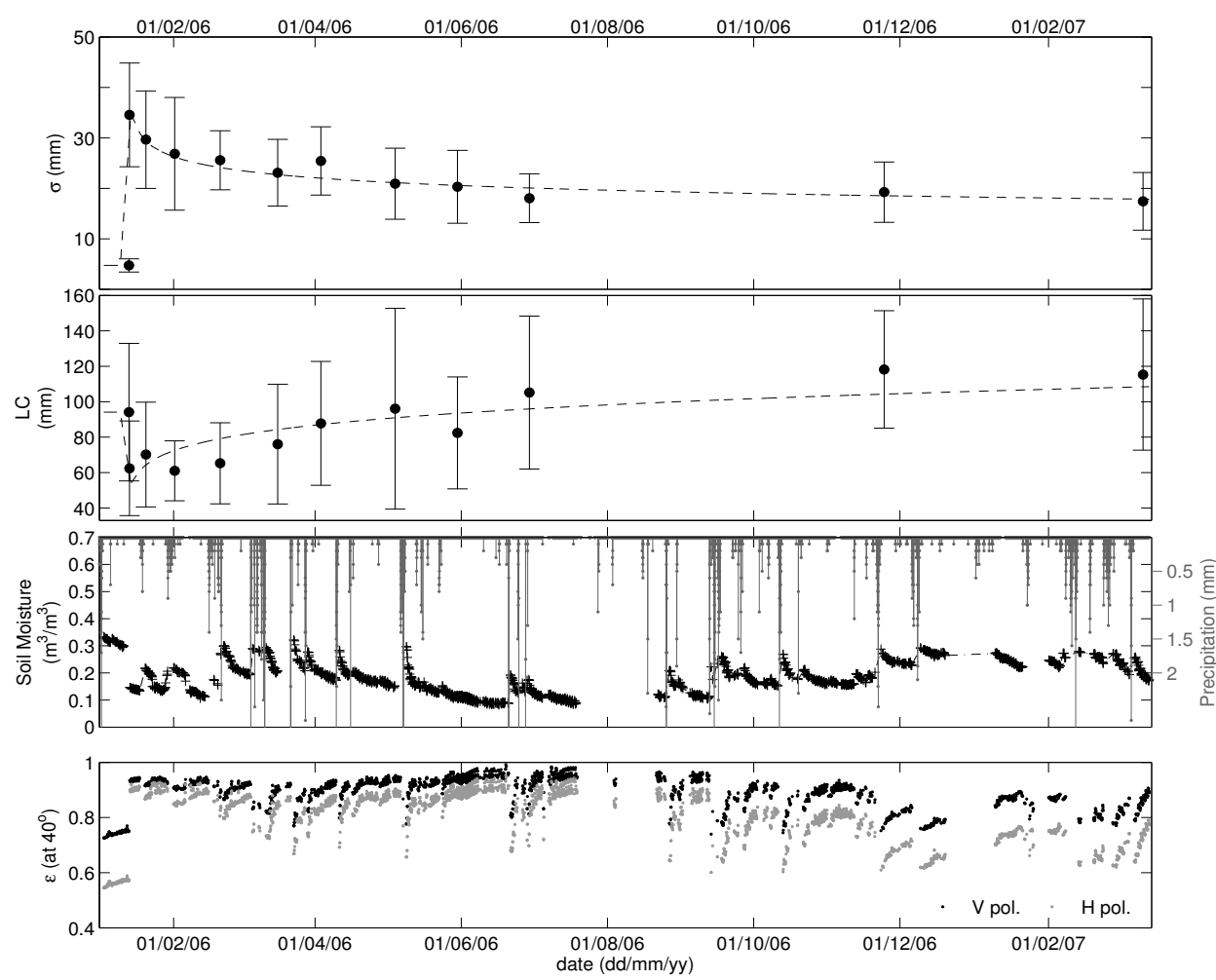

Fig. 1. Time series of surface parameters from December 2005 to March 2007. Top Fig. is $\sigma$ (in $\mathrm{mm}$ ) and its standard deviation ; The surface was ploughed the 13th of January 2006. 2nd from the top: the correlation length ; 3rd panel: soil moisture (black x, left hand y-axis) and precipitation (grey sticks, right hand y-axis, note that it is inversed for graphical convenience) ; Bottom figure is the emissivities at $\mathrm{V}$ (black dots) and $\mathrm{H}$ (grey dots) polarizations monitored by Lewis radiomater at an incidence angle of $40^{\circ}$.
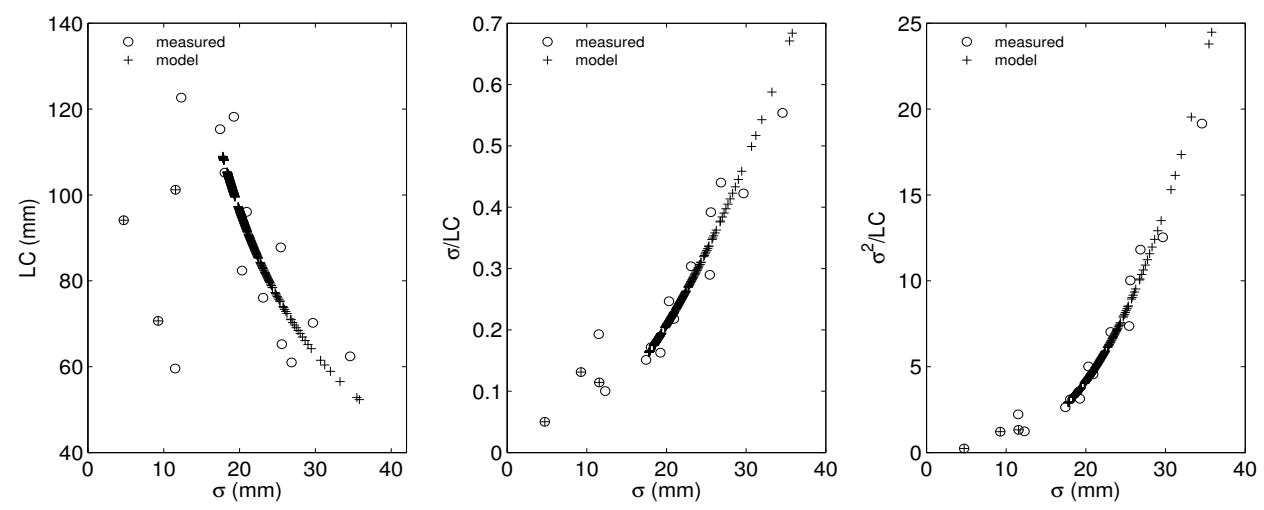

Fig. 2. LC, $\sigma / \mathrm{LC}$ and $\sigma^{2} / \mathrm{LC}$ as a function of $\sigma$. For each case are displayed: the measured $\sigma$ and LC (Table I), "o" symbols and referred to as "measured " in the legends; $\sigma$ and LC obtained from Eq. 5 and 6," +" symbols and referred to as "modeled" in the legends. Measured and model data are similar for data acquired before ploughing the surface.

difference between the emissivities at $\mathrm{H}$ and $\mathrm{V}$ pass larization increases with increasing incidence angleag for each wetness conditions but is decreased witho roughness. Furthermore, the impact of roughness 1 on the emissivity is more pronounced at $\mathrm{H}$ than $\mathrm{V}$ polarization. At the incidence angle of $40^{\circ}$, the emissivity at $\mathrm{H}$ pol. is $\sim 0.56$ at a soil moisture content of $0.3 \mathrm{~m}^{3} / \mathrm{m}^{3}$ and for a smooth surface (3rds line, right hand side Fig. 3 ) whereas it is $\sim 0.8$ for a rough surface (left hand side Fig. 3). It corresponds to an increase in the emissivity of 0.24 , whereas for the $\mathrm{V}$ polarization this increase is $\sim 0.145$, from an emissivity of $\sim 0.72$ for flat condition to $\sim 0.865$ for a rough surface. The decrease in the emissivity with soil moisture has a linear trend for rough conditions and for each incidence angle (left-hand columns Fig. 3), the effect being again more pronounced at $\mathrm{H}$ polarization than at $\mathrm{V}$ polarization. 


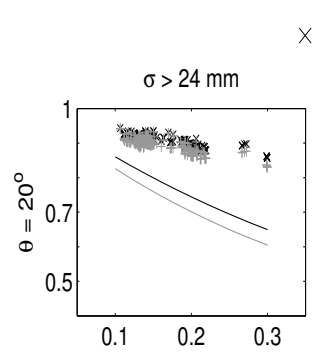

$\times \mathrm{V}+\mathrm{H}-\mathrm{V}_{0, \text { Fresnel }} \longrightarrow \mathrm{H}_{0, \text { Fresnel }}$
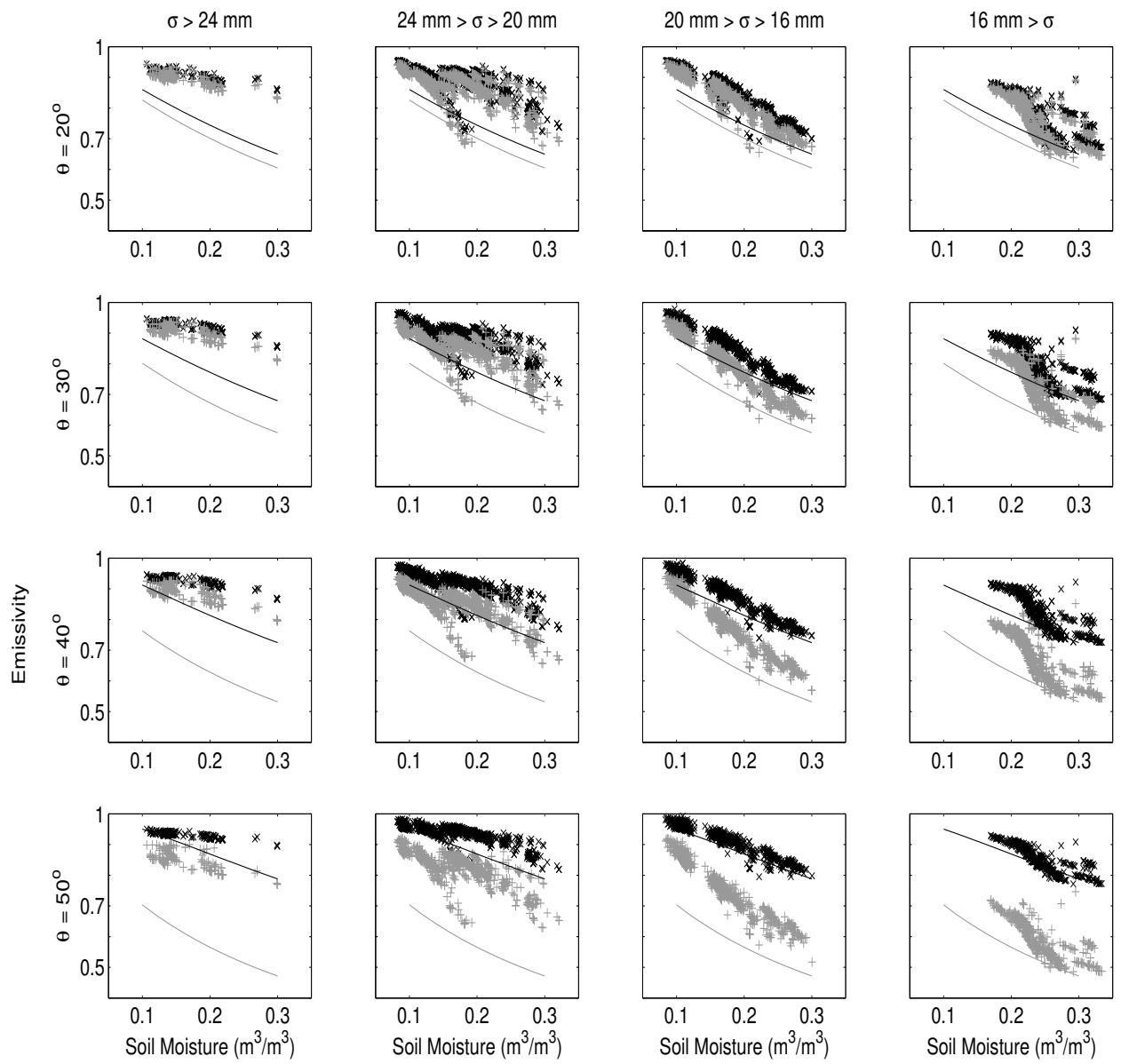

Fig. 3. Emissivity at $\mathrm{V}($ black $\mathrm{x})$ and $\mathrm{H}($ grey +$)$ polarizations, monitored at 4 incidence angles as a function of soil moisture : $20^{\circ}$ (top row figures), $30^{\circ}$ ( 2 nd row), $40^{\circ}$ (3rd row) and $50^{\circ}$ (bottom row). The 4 columns correspond to roughness conditions, from a very rough surface -1 st column from the left- to quasi-smooth condition (right hand side column). Emissivity computed from Fresnel's law (flat surface) is shown as black (V pol.) and grey ( $\mathrm{H}$ pol.) continuous lines.

\section{L-Meb model calibration}

The second objective of this paper is to use the database to study the roughness parameters $\left(\mathrm{Q}^{408}\right.$ $\mathrm{Hr}, \mathrm{N}_{H}$ and $\mathrm{N}_{V}$ ) as defined in Eq. 2.

1) Relation between $N_{H}$ and $N_{V}: \Delta \mathrm{N}$ is derived 1 from Eq. 3 and presented in Fig. 4 as a function $\sigma f^{2}$ $\sigma$ values estimated by the fit function (Eq. 5 anख 3 grey dashed line Fig. 1). The use of the fit instead of actual values is done to limit errors caused bys sampling limits in characterizing the field (2nq6 board and $\sim 8$ samples per day). Fig. 4 clearlyg7 shows a decreasing trend of $\Delta \mathrm{N}$ with $\sigma$, well 8 represented by the linear function defined as $\Delta \mathrm{N}_{9}$ $=\mathrm{N}_{H}-\mathrm{N}_{V}=-0.049 . \sigma+2.188(\mathrm{R}=0.90$, RMSE 0 $=0.16$, bias $=0)$. Smoother surface, i.e. $\sigma<161$ $\mathrm{mm}$, is characterized by a $\Delta \mathrm{N}$ of $\sim 1.8$, which is 2 in agreement with $\Delta \mathrm{N}=2$ found previously [18],3 whereas it is $\sim 0.5$ for very rough surface, i.e. $\sigma \gg 4$ $35 \mathrm{~mm}$. This trend is close to that obtained in $[13]_{5}$
$(\Delta \mathrm{N}=-0.036 \times \sigma+2.24)$ over another agricultural site.

2) Retrieved parameters: $\mathrm{N}_{p}(\mathrm{p}=\mathrm{H}$ or $\mathrm{V}), \mathrm{Qr}$ and $\mathrm{Hr}$ (Eq. 2) were derived from Eq. 4, for every day over the period November 2005-April 2007. The emissivity computed using these parameters, leads to an $\mathrm{RMSE}=0.022\left(\mathrm{R}^{2}=0.95\right)$ when compared to LEWIS emissivity, whereas an RMSE = $0.053\left(\mathrm{R}^{2}=0.69\right)$ is encountered when applying the parameters found by Escorihuela et al. [18] over a flat surface. Fig. 5 presents the retrieved roughness parameters Qr (top Fig.), $\mathrm{Hr}$ (middle Fig.) and $\mathrm{N}_{H}$ and $\mathrm{N}_{V}$ (bottom Fig.) for case $\mathrm{B}$ as a function of time. The time variation in $\sigma$ and its best fit trend (Eq. 5) are also showed for comparison. Hr presents a high variability, but in general it decreases as $\sigma$ decreases.

The high variability in the retrieved values of $\mathrm{Hr}$ could be linked to the fact that this parameter 


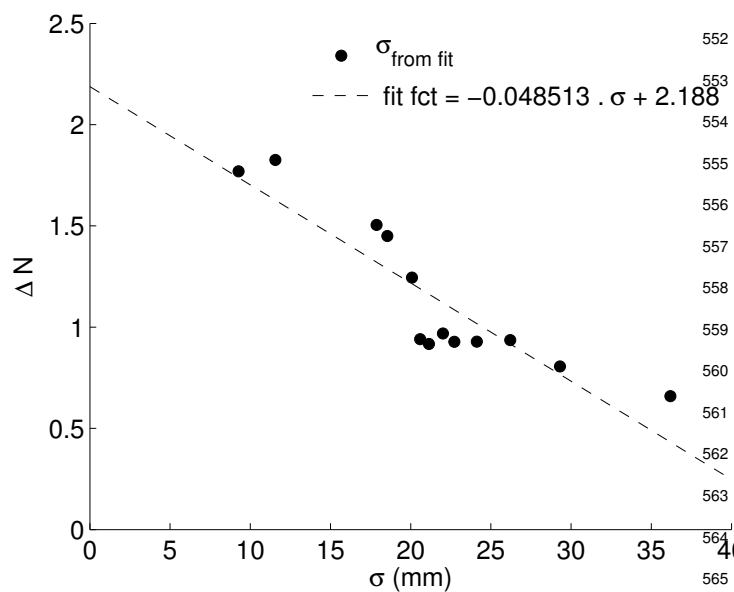

Fig. 4. $\sigma$ estimated from roughness measurements plotted against $\Delta \mathrm{N}$ (black $\bullet$ ) calculated from LEWIS data, including the linear fit function (dashed line).

tends to compensate for the difference between the sampling depth [23] [37] of the in-situ soil moisture sensors $(\sim 0-6 \mathrm{~cm} \text { top soil layer })_{4}$ and of the LEWIS observations $\left(\sim 0-2 / 3 \mathrm{~cm}_{3,5}\right.$ For example after a rain event following dry soil moisture conditions, the LEWIS observations, immediately show a clear decrease in the monitored, brightness temperatures whereas the in-situ probe still measures a low water content. Whilst LEWIS, is sensitive to the first $0-2 / 3 \mathrm{~cm}$, which is wet after a rain event, the probe integrates the soil moisture between the surface layer which is wet and ${ }_{53}$ deeper layer which is dryer. In this case, the soil moisture estimated by the probe is underestimated in comparison to the soil moisture seen by LEWIS The L-MEB model uses this underestimated soil moisture and compensates this effect by adjusting $\mathrm{Hr}$ to fit the LEWIS observations. Such effects may explain the high variability in the retrieved values of $\mathrm{Hr}$ obtained in May, July, September, 2006. The opposite situation is also observed (dry surface over the $0-2 / 3 \mathrm{~cm}$ surface layer and rather wet conditions over the $0-6 \mathrm{~cm}$ surfaces layer) and could explain high retrieved values, of $\mathrm{Hr}$ obtained in March 2004 and November 2005

The results of the retrieval are presented as atr function of the estimated $\sigma$ (Eq. 5, dashed linee top Fig. 1) and LC (Eq. 6) in Fig. 6 and Fig. 579 (grey markers for the case A with Qr=0 and blackso markers for the case B where Qr is retrieved gar $_{0}$ We also studied the derived parameters with the quantity $\sigma / \mathrm{LC}$ (not shown here), but the resultss are very similar to the results presented in Fig. 604 Qr (case B, it is retrieved, black $\bullet$ Top left Fig. 6. $)_{5}$ increases significantly from values around 0.05 faro a flat surface to 0.3 for a rough surface. A Low Qr value for a quasi-smooth surface is in agreement with both theory (no polarization mixing, [11]) and observations [13] [18]. It confirms also that $\mathrm{Qr}$ is not equal to 0 for rough surface and needs to be taken into account to model the signature of rough soils. Retrieved values of $\mathrm{Hr}$ (Top right Fig. 6) show more variability as mentioned earlier. They evolve on average from $\sim 0.2-0.3$ for a smooth surface to $\sim 1$ for a rough surface. The relation $\mathrm{Hr}=\mathrm{f}(\sigma)$ obtained in [13] is represented by the dashed line, fitting the results of the presented study. It is interesting to note that this relationship obtained for different conditions over a different site and a variety of soil roughness conditions provide a good general fit to the results obtained in this study. These results confirm that the empirical relationship $\mathrm{Hr}=(2 k \sigma)^{2}$ [9] (dotted line Fig. 6) is not applicable, also found in [13]. Retrieved values of $\mathrm{Hr}$ when $\mathrm{Qr}, \mathrm{Hr}$ and $\mathrm{Np}(\mathrm{p}=\mathrm{H}$ or $\mathrm{V})$ are retrieved are higher than when $\mathrm{Qr}$ is set equal to 0 . $\mathrm{Qr}$ and $\mathrm{Hr}$ variations seem to be correlated to variations in $\sigma$ whereas no clear correlation with $\sigma$ could be found for $\mathrm{N}_{V}$ and $\mathrm{N}_{H}$ (bottom left Fig. 6) confirming the observations of [13]. $\mathrm{N}_{H}$ and $\mathrm{N}_{V}$ are found on average to be equal to 2.8 and 1 respectively for a smooth surface whereas the authors of [18] set them to lower values of 1 and -1. For rough surface however, $\mathrm{N}_{H}$ and $\mathrm{N}_{V}$ do not vary and can clearly be set to $\mathrm{N}_{H}=0.59$ and $\mathrm{N}_{V}=-0.30$. Q seems related to $\mathrm{Hr}$ (bottom right Fig. 6) by the relation $\mathrm{H}=2.69^{*} \mathrm{Q}(\mathrm{R}=0.71)$. Eq. 2 imposes the conditions $\mathrm{Q}=0$ for $\mathrm{H}=0$, meaning the emissivity of a flat surface is that from Fresnel's law.

The retrieved parameters show the opposite behavior when studied as a function of LC (Fig. 7) with $\mathrm{Hr}$ and $\mathrm{Q}$ decreasing with increasing LC. $N_{V}$ and $N_{H}$ present less variations for a rough surface (low LC) than in Fig. 6.

\section{Conclusions and Perspectives}

Roughness effects at L-band are complex and need more investigations to be fully understood and modeled [13; 38]. This paper presents the unique SMOSREX-2006 experimental database dedicated to study the effect of roughness at L-band over 14 months. A bare soil has been significantly ploughed at the SMOSREX site and continuously monitored by LEWIS L-band radiometer. It has been found that the influence of roughness is more important at high incidence angles (about 40 to $50^{\circ}$ ), high soil moisture values and at $\mathrm{H}$ polarization. 

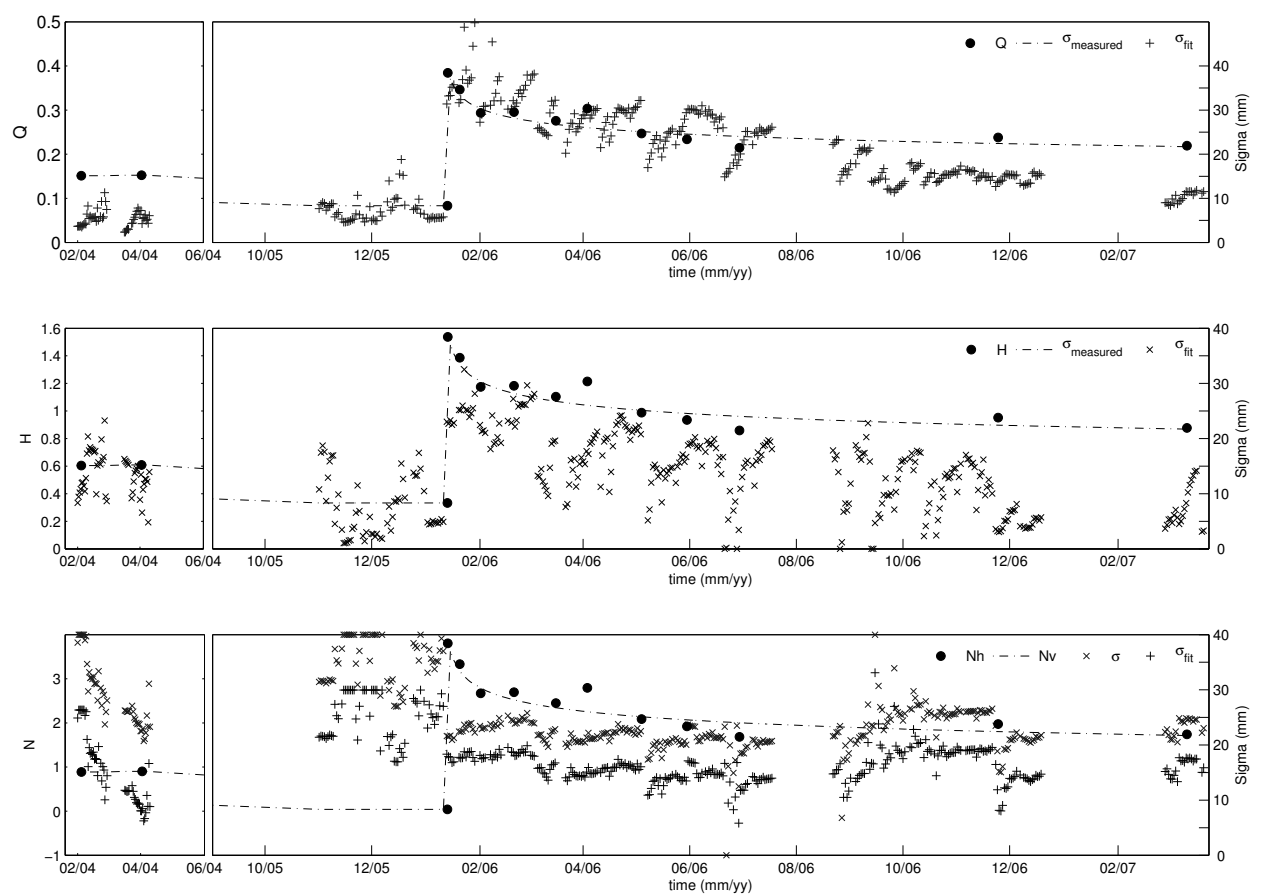

Fig. 5. Time series of the roughness parameters of Eq. 2. Top figure shows Qr, middle figure shows $\mathrm{Hr}$ and the bottom figure presents $\mathrm{N}_{H}$ (x) and $\mathrm{N}_{V}(+) . \sigma$ and its fit trend (Eq. 5) are also depicted (with right hand side y-axis). The time series are split in two panels (left and right hand columns) as the time series are not continuous (no roughness measurement in 2005).

The soil moisture derived from the SMOS。 mission is based on a semi-empirical approacka [8] and the roughness effect is taken into accounts by the Q-H model $[9 ; 13 ; 18]$. The presented database is also used to study the semi-empiricalo parameters of the L-MEB emission model as at function of surface characteristics represented 2 by $\sigma$ and LC. The results of this study suggest that for a rough surface $\mathrm{Qr}=0.3, \mathrm{Hr} \sim=1, \mathrm{~N}_{H^{E+4}}$ 0.59 and $\mathrm{N}_{V}=-0.30$, whereas a smooth surfaces is characterized by $\mathrm{Qr} \sim 0.05, \mathrm{Hr} \sim 0.2 / 0.3, \mathrm{~N}_{H+6}$ $\sim 2.8$ and $N_{V} \sim 1$. It is different from most of the previous works on the subject which set $\mathrm{Q}=0$ even for rough conditions. A simple model can not have been found to represent the dependences of the semi-empirical parameters with $\sigma$ and LE9 due to their high variability, especially in case 0 of Hr. However, it is interesting to note that the $\sigma-\mathrm{Hr}$ relation proposed by [13] seems to be ${ }^{2}$ applicable here over SMOSREX conditions. A linear relationship between $\mathrm{N}_{H}$ and $\mathrm{N}_{V}$ is als $\oint_{3}$ found, with the difference $\mathrm{N}_{H}-\mathrm{N}_{V}$ decreasing with $\sigma$. The variations of these semi-empiricát parameters can be explained by the difference ${ }^{655}$ in sampling depth between the sensors that are not sensitive to the same surface layer. This difference can be reduced by selecting some certain weather and soil moisture conditions. After an important rainfall the soil reaches its field capacity and is more homogeneous in terms of soil moisture content as both the $0-2 / 3 \mathrm{~cm}$ top layer (as monitored by LEWIS) and the top $0-6 \mathrm{~cm}$ (as monitored by the probes) should have the same soil moisture content. After a drying period, the soil reaches its lower soil moisture content and both the probes and LEWIS monitor the same amount of soil moisture. By extracting those specific periods, it is expected to reduce the variability of the derived parameters.

\section{ACKNOWLEDGMENT}

The authors would like to thank the SMOSREX parteners Météo-France and ONERA. This experiment was funded by Programme National de Télédétection Spatiale and Terre Océan Surfaces Continentales et Atmosphère.

\section{REFERENCES}

[1] Y. H. Kerr, "Soil moisture from space: Where are we?" Hydrogeology Journal, vol. 15, pp. 117-120, 2007.

[2] Y. H. Kerr, P. Waldteufel, J.-P. Wigneron, J. Font, and M. Berger, "Soil moisture retrieval from space : the soil moisture ant ocean salinity (smos) mission," IEEE T. Geosci. Remote, vol. 39(8), pp. 1729-1735, 2001. 

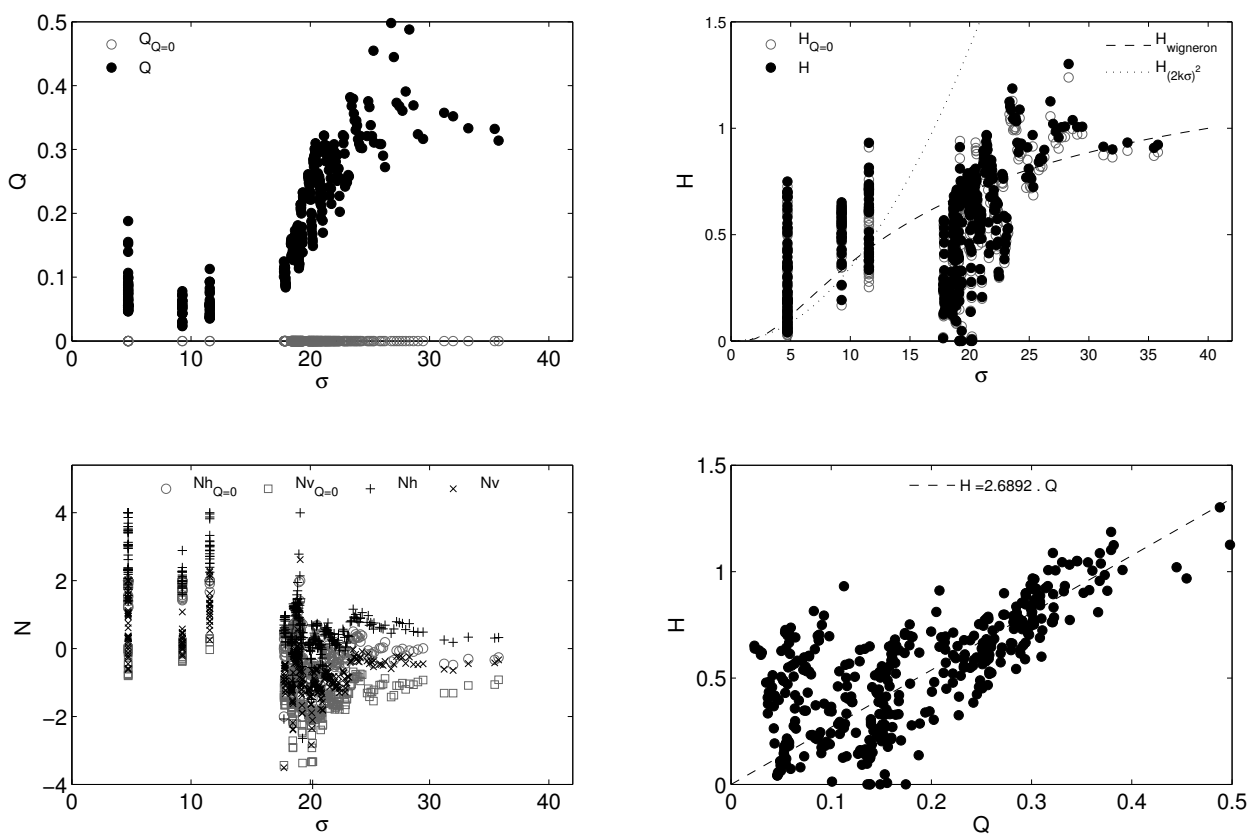

Fig. 6. Retrieved $\mathrm{Qr}, \mathrm{Hr}$ and $N_{p}(\mathrm{p}=\mathrm{V}$ or $\mathrm{H})$ as a function of estimated $\sigma$ (i.e. Eq. 5). Two cases considered : A) $\mathrm{Qr}=0$, $\mathrm{Hr}$ and $N_{p}(\mathrm{p}=\mathrm{V}$ or $\mathrm{H})$ are derived (grey markers on all Figure); B) $\mathrm{Qr}$ is derived (black markers). In the top right figure are also depicted $\mathrm{H}$ functions as found in i) Wigneron et al. 2011 [13] (dashed line) and ii) $\mathrm{Hr}=(2 k \sigma)^{2}$ [9] (dotted line).

[3] Y. H. Kerr, P. Waldteufel, P. Richaumeg2 J.-P. Wigneron, P. Ferrazzoli, and R. Gurneyga "SMOS level 2 processor for soil moisture4 - Algorithm Theoretical Based Documents (ATBD) ," CBSA, Tech. Rep. SO-TN696 ESL-SM-GS-0001， Issue 3.e, 2011， 1267 p. [Online]. Available: http://www.cesbiøss ups-tlse.fr/fr/indexsmos.html

[4] Y. H. Kerr, J. Font, P. Waldteufel, A. Campsqo J. Bara, I. Corbella, F. Torres, N. Duffog, M. Vall.llossera, and G. Caudal, "Next2 Generation radiometers: SMOS a dual pod 3 L-band 2D aperture synthesis radiometer;04 P.Pampaloni and S. Paloscia, Eds., Utrecht ${ }_{95}$ The Netherlands, pp. 447-483, 2000.

[5] J.-P. Wigneron, J.-C. Calvet, T. Pellarina7 A. Van de Griend, M. Berger, and P. Felos razzoli, "Retrieving near surface soil moisos ture from microwave radiometric observa +o tions: Current status and future plans," Remote 1 Sens. Environnement, vol. 85, pp. 489-506, 2003.

[6] J.-P. Wigneron, J.-C. Calvet, P. de Rosnay,4 Y. H. Kerr, P. Waldteufel, K. Saleh, Mz+5 J. Escorihuela, and A. Kruszewski, "Soi16 moisture retrievals from biangular $\mathrm{L}_{7+7}$ band passive microwave observations $\not{ }_{18}$ Geoscience and Remote Sensing Letter $\$_{19}$ IEEE, vol. 1(4), pp. 277-281, 2004, doi=10.1109/LGRS.2004.834594.
[7] J.-P. Wigneron, Y. H. Kerr, P. Waldteufel, K. Saleh, M.-J. Escorihuela, P. Richaume, P. Ferrazzoli, P. de Rosnay, R. Gurney, J.C. Calvet, J. P. Grant, M. Guglielmetti, B. Hornbuckle, C. Mätzler, T. Pellarin, and M. Schwank, "L-band Microwave Emission of the Biosphere (L-MEB) Model : Description and calibration against experimental data sets over crop fields," Rem. Sens. Environ., vol. 107, pp. 639-655, 2007.

[8] Y. H. Kerr, P. Waldteufel, P. Richaume, A. Mahmoodi, J.-P. Wigneron, P. Ferrazzoli, A. Al bitar, F. Cabot, D. Leroux, A. Mialon, and S. Delwart, "The SMOS soil moisture retrieval algorithm," IEEE Geosc. Remote Sens., 2011, submitted.

[9] B. Choudhury, T. Schmugge, A. Chang, and R. Newton, "Effect of surface Roughness on the microwave emission from soil ,"J. Geophys. Res., vol. 84, no C9, pp. 5699-5706, 1979.

[10] J. R. Wang and B. J. Choudhury, "Remote sensing of soil moisture content over bare fields at $1.4 \mathrm{GHz}$ frequency," J. Geophys. Res., vol. 86, pp. 5277-5282, 1981.

[11] J. Shi, K. S. Chen, Q. Li, T. J. Jackson, P. E. O'Neill, and L. Tsnag, "A parameterized surface reflectivity model and estimation of bare-surface soil moisture with L-band radiometer," IEEE T. Geosci. Re- 

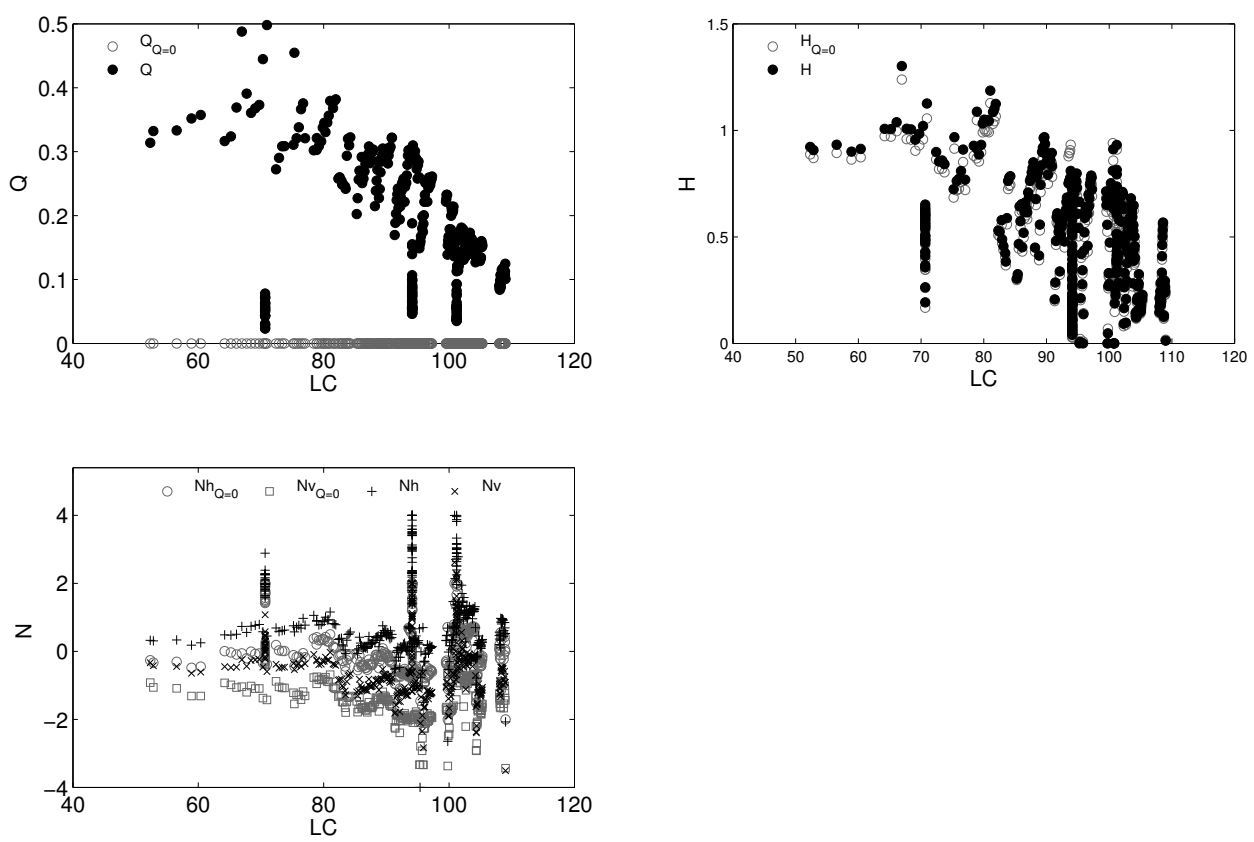

Fig. 7. Retrieved Qr, $\mathrm{Hr}$ and $N_{p}(\mathrm{p}=\mathrm{V}$ or $\mathrm{H})$ as a function of estimated LC (i.e. Eq. 6). Two cases considered : A) Qr=0, $\mathrm{Hr}$ and $N_{p}(\mathrm{p}=\mathrm{V}$ or $\mathrm{H})$ are derived (grey markers) B) $\mathrm{Qr}$ is derived (black markers on all Fig.).

mote, vol. 40 (no 12), pp. 2674-2686, 2002 $2_{53}$ doi $=10.1109 /$ TGRS.2002.807003.

[12] J. R. Wang, P. E. O’Neill, T. J. Jackson, ands E. T. Engman, "Multifrequency measurements ${ }_{6}$ of the effects of soil moisture, soil texture ${ }_{57}$ and surface roughness," IEEE Trans. Geoses8 Remote Sensing, vol. vol.21, pp. 44-51, 199359

[13] J.-P. Wigneron, A. Chanzy, Y. H. Kerføo H. Lawrence, J. Shi, M.-J. Escorihuelaş1 V. Mironov, A. Mialon, F. Demontoux ${ }_{92}$ P. de Rosnay, and K. Saleh-Contell, "Evalsз uating an Improved Parameterization of thes Soil Emission in L-MEB," IEEE Geosci, Remote, vol. 49 (4), pp. 1175-1189, $2011_{196}$ doi=10.1109/TGRS.2010.2075935.

[14] R. Panciera, J. P. Walker, J. Kalma, E. J. Kimą, K. Saleh, and J.-P. Wigneron, "Evaluation of the SMOS L-MEB passive microwave soito moisture retrieval algorithm," Remote Sensing 1 of Environment, vol. 113, no. 2, pp. 435 - 444 $4_{32}$ 2009, doi:10.1016/j.rse.2008.10.010.

[15] K. Saleh, Y. H. Kerr, P. Richaume, M ${ }_{774}$ J. Escorihuela, R. Panciera, S. Delwart, G. Boulet, P. Maisongrande, J. P. Walker, P. Wursteisen, and J.-P. Wigneron, "Soil mois77 ture retrievals at L-band using a two-steps inversion approach (COSMOS/NAFE'05 Ex=9 periment)," Remote Sensing of Environment;o vol. 113, no. 6, pp. 1304 - 1312, 2009, dOts 10.1016/j.rse.2009.02.013.

[16] A. Cano, K. Saleh, J.-P. Wigneron, C. Antolín̨s
J. E. Balling, Y. H. Kerr, A. Kruszewski, C. Millán-Scheiding, and S. Søbjæg, "The smos mediterranean ecosystem 1-band characterisation experiment (melbex-i) over natural shrubs," Remote Sensing of Environment, vol. 114 , no. 4, pp. 844 - 853, 2010, dOI: 10.1016/j.rse.2009.11.019.

[17] J.-P. Wigneron, L. Laguerre, and Y. H. Kerr, "A simple parameterization of the L-band microwave emission from rough agricultural soils," Geoscience and Remote Sensing, IEEE Transactions on, vol. 39(8), pp. 1697-1707, 2001, doi=10.1109/36.942548.

[18] M. Escorihuela, Y. Kerr, P. de Rosnay, J. Wigneron, J. Calvet, and F. Lemaître, "A Simple Model of the Bare Soil Microwave Emission at L-Band," IEEE T. Geosci. Remote, vol. 45 (vol 7, Part 1), pp. 1978-1987, 2007.

[19] P. de Rosnay, J. Calvet, Y. Kerr, J. Wigneron, F. Lemaître, M. Escorihuela, J. Sabater, K. Saleh, J. Barrié, G. Bouhours et al., "SMOSREX: A long term field campaign experiment for soil moisture and land surface processes remote sensing," Remote Sens. Environ., vol. vol.102 (n 3-4), pp. p377-389, 2006.

[20] K. Saleh, J.-P. Wigneron, P. Waldteufel, P. de Rosnay, M. Schwank, J.-C. Calvet, and Y. H. Kerr, "Estimates of surface soil moisture under grass covers using 1-band radiometry," Remote Sensing of Environment, 
vol. 109, no. 1, pp. 42 - 53, 2007, dOІзेง 10.1016/j.rse.2006.12.002.

[21] F. Lemaître, J.-C. Poussière, Y. H. Kers M. Dejus, R. Durbe, P. de Rosnay, and $\mathrm{J}_{8 \neq 2}$ C. Calvet, "Design and test of the ground ${ }_{* 3}$ based L-band Radiometer for Estimating $\mathrm{Wa}_{\star 4}$ ter In Soils (LEWIS)," IEEE T. Geosci. Re 645 mote, vol. 42 (8), pp. 1666-1676, 2004 446 doi=10.1109/TGRS.2004.831230.

[22] T. J. Schmugge, T. J. Jackson, and $\mathrm{d}_{3}$ H. McKim, "Survey of methods for soils moisture determination," Water Resou\&50 Res., vol. 16(6), pp. 961-979, 1980 doi:10.1029/WR016i006p00961.

[23] M. Escorihuela, A. Chanzy, J. Wigneron, and Y. H. Kerr, "Effective soil moisture sam ${ }_{54}$ pling depth of 1-band radiometry: A cases study," Remote Sensing of Environment, vod56 114, no. 5, pp. 995 - 1001, 2010, dOI57 10.1016/j.rse.2009.12.011.

[24] F. T. Ulaby, R. K. Moore, and A. K. Fung, Miss crowave remote sensing, active and passive60 Dedham, MA, USA : Artech house, 1982, vol. 2 : Radar Remote Sensing and Surfaces Scattering and Emission Theory.

[25] N. E. C. Verhoest, H. Lievens, W. Wagne ${ }_{64}^{4}$ J. Àlvarez-Mozos, M. Moran, and F. Mattią5 "On the soil roughness parameterization probø6 lem in soil moisture retrieval of bare surfaces 7 from synthetic aperture radar," Sensors, vol. $8_{98}$ pp. 4213-4248, 2008, dOI 10.3390/s807421369

[26] M. Schwank, I. Völksch, J.-P. Wigneronzo Y. H. Kerr, A. Mialon, P. de Rosnay, and C. Mätzler, "Comparison of two Barezz Soil Reflectivity Models and Validation With L-Band Radiometer Measurements\$74 IEEE Trans. Geosci. Remote Sensing ${ }_{35}$ vol. 48(1), pp. 325-337, 2010, dOI 10.1109/TGRS.2009.2026894.

877

[27] H. Lawrence, J.-P. Wigneron, F. Demontoux 38 A. Mialon, and Y. H. Kerr, "Evaluation the semi-empirical H-Q model, used to calculateo the emissivity of a rough bare soil, with numerical modeling approach," IEEE Trans82 Remote Sens., 2011, submitted.

[28] F. T. Ulaby, R. K. Moore, and A. K. Fung $g_{94}$ Microwave remote sensing, active and pas85 sive. Dedham, MA, USA : Artech houses6 1986, vol. 3 : From Theory to Applications ${ }_{887}$

[29] P. de Rosnay, J. Wigneron, T. Holmes, ands J. Calvet, "Parametrizations of the effecss tive temperature for L-band radiometry. Intekso comparison and long term validation wita1 SMOSREX field experiment," in C. Mätzlesb2 (Eds) Thermal microwave radiation - Applïэ cations for remote sensing . London, UK: IEE Electromagnetic Waves Series, 2006.

[30] T. Pellarin, J.-P. Wigneron, J.-C. Calvet, M. Berger, H. Douville, P. Ferrazzoli, Y. H. Kerr, E. Lopez-Baeza, J. Pulliainen, L. Simmonds, and P. Waldteufel, "Two-years global simulation of the L-band brightness temperature over land," IEEE T. Geosci. Remote, pp. p2135-2139, 2003.

[31] V. L. Mironov and S. V. Fomin, "Temperature and Mineralogy Dependable Model for Microwave dielectric Spectra of Moist Soils," PIERS Online, vol. Vol. 5, N. 5, pp. 411-415, 2009, doi:10.2529/PIERS090220054025.

[32] V. L. Mironov, L. G. Kosolapova, and S. V. Fomin, "Physically and mineralogically based spectroscopic dielectric model for moist soils," IEEE Trans. Geosci. Remote Sensing, vol. Vol. 47, N. 7, pp. 2059-2070, 2009.

[33] M. Dobson, F. Ulaby, M. Hallikainen, and M. El-Rayes, "Microwave dielectric behavior of wet soil-part ii: Dielectric mixing models," IEEE T Geosci. Remote, vol. GE-23, no. 1, pp. 35-46, 1985.

[34] N. Peplinski, F. Ulaby, and M. Dobson, "Dielectric properties of soils in the $0.3-1.3-\mathrm{GHz}$ range," IEEE T. Geosci. Remote, vol. 33, no. 3, pp. 803-807, 1995.

[35] C. Prigent, J. Wigneron, W. Rossow, and J. Pardo-Carrion, "Frequency and angular variations of land surface microwave emissivities: can we estimate SSM/T and AMSU emissivities from SSM/I emissivities," IEEE T. Geosci. Remote, vol. 38, pp. 2373-2386, 2000.

[36] Q. Li, L. Tsang, J. Shi, and C. H. Chan, "Application of physics-based two-grid method and sparse matrix canonical grid method for numerical simulations of emissivities of soils with rough surfaces at microwave frequencies," Geoscience and Remote Sensing, IEEE Transactions on, vol. 38, no. 4, pp. 1635 1643, 2000, dOI : 10.1109/36.851963.

[37] S. Raju, A. Chanzy, J.-P. Wigneron, J.-C. Calvet, Y. H. Kerr, and L. Laguerre, "Soil moisture and temperature profile effects on microwave emission at low frequencies," $R e$ mote Sensing of Environment, vol. 54, no. 2, pp. 85 - 97, 1995, dOI: 10.1016/00344257(95)00133-L.

[38] H. Lawrence, F. Demontoux, J.-P. Wigneron, P. Paillou, T.-D. Wu, and Y. H. Kerr, "Evaluation of a Numerical Modeling Approach based on the Finite Element Method for calculating the Rough Surface Scattering and Emission 

ceived the M.S. degree in climate ariat physics-chemistry of the atmosphere $\mathrm{in}^{8}$ 2002 and a Ph.D. degree in ocear ${ }^{59}$ atmosphere-hydrology from Universieg Joseph Fourier de Grenoble (France9 1 and a Ph.D. in remote sensing froff ${ }^{2}$ the Université de Sherbrooke (Québee, Canada) in 2005. He joined the Centre d'Etudes Spatiales de la Biosphèré, Toulouse, France, in 2006. His fielas of interest are focused on passive microwave remote sensing $\mathrm{g}^{7}$ of continental surfaces. He has been involved in the SMOs ${ }^{8}$ (Soil Moisture and Ocean Salinity) mission since 2006 and $99^{9}$ in charge of the experimental site of SMOSREX since 2007. ${ }^{970}$

Jean-Pierre Wigneron Jean-Piere区 Wigneron (SM 03) received tppe Engineering degree from SupAér8, Ecole Nationale Supérieure đ\&0 l'Aéronautique et de l'Espaes' (ENSAE), Toulouse, France, in 19892 and the Ph.D. degree from University of Toulouse, France, in 1993. He is currently a Senior Research Scientist at the Institut National de Recherche Agronomiques (INRA), Bordeaux, France, and the Head of the remote sensing group at EPHYSE, Bordeaux. He coordinated the development of the L-MEB model for soil and vegetation in the Level-2 inversion algorithm of the ESA-SMOS Mission. His research interests are in microwave remote sensing of soil and vegetation, radiative transfer, and data assimilation. He was a Principal Investigat ${ }^{3}{ }^{3}$ of several international campaigns in the field of microwaves remote sensing. He has over 70 refereed papers in remoes sensing. He has been a member of the Editorial Board $\$ \$ 6$ Remote Sensing of Environment since 2005.

\begin{tabular}{|l|l|}
\cline { 2 - 2 } 932 & \\
933 & \\
934 & \\
935 & \\
936 & PLACE \\
937 & PHOTO \\
938 & HERE \\
939 & \\
940 & \\
941 & \\
\hline 992
\end{tabular}
the engineering Yann H. Kerr received the M.Sc. from Glasgow Universieg6 in E\&EE, and Ph.D from Universieg Paul Sabatier. From 1980 to 1985 pes was employed by CNES. In 1985 1яе9 joined LERTS. He spent 19 months rato JPL, Pasadena in 1987-88. He has betn 1 working at CESBIO since 1995 . Higs fields of interest are in the theory and 3 techniques for microwave and thermad4 infrared remote sensing of the Earth, with emphasis on hydrolos ogy, water resources management and vegetation monitoring. He was an EOS principal investigator (interdisciplinary investigations). He was the science lead on the MIRAS project for ESA, and is now the of the SMOS mission Lead-Investigator.

\begin{tabular}{|c|}
\hline \\
PLACE \\
PHOTO \\
HERE \\
\end{tabular}

Patricia de Rosnay Patricia de Rosnay received her $\mathrm{Ph} . \mathrm{D}$ degree in climate modelling from the University Pierre et Marie Curie (Paris 6, France) in 1999. She is currently Senior Scientist with the European Centre for Medium-Range Weather Forecasts (ECMWF) where is responsible of the land surface data assimilation activities. Her current research interests focus on improving soil moisture and snow analysis for Numerical Weather Prediction. She developed and implemented a 2-Dimensional Optimum Interpolation snow analysis and also implemented in operations an Extended Kalman Filter soil moisture analysis at ECMWF and she is investigating the use of passive and active microwave satellite data for Numerical Weather Prediction. She is involved in the SMOS Validation and Retrieval Team and participates to the EUMETSAT H-SAF project. She is member of the Science Definition Team and the Application Working Group of the future NASA SMAP mission and member of the SRNWP surface team. She was involved in land surface modelling activities such as the African Monsoon Multidisciplinary Analysis (AMMA) Land Surface Model Inter-comparison Project (ALMIP) and she coordinated the microwave component of the project ALMIPMEM (Microwave Emission Model). She initiated the project for the validation of the future SMOS soil moisture products over West Africa. Patricia de Rosnay worked five years with the French Centre National de la Recherche Scientifiques (CNRS) at Centre d'Etudes Spatiales de la Biosphère (CESBIO), Toulouse, France, where she coordinated the SMOSREX field experiment in preparation of SMOS. Her research topic at the Laboratoire de Météorologie Dynamique (LMD) from 1994 to 2002 was focused on developments of global scale land surface processes representation in climate models.

\begin{tabular}{|c|}
\hline \\
PLACE \\
PHOTO \\
HERE \\
\end{tabular}

Maria Jose Escorihuela Maria Jose Escorihuela received an Engineering degree in electronics and telecommunications from the Universitat Politècnica de Catalunya (UPC) in 1996 and a $\mathrm{Ph}$. D. degree in Environmental, Space and Universe Sciences from the Institut National Polytechnique in Toulouse (France) in 2006. From 2003 to 2006, she was in the Centre d'Etudes Spatiales de la Biosphère (CESBIO) in Toulouse, France, where she developed models of natural surfaces emission at L-band for soil moisture estimation in the framework of the Soil Moisture and Ocean Salinity (SMOS) mission. In 2007 she was a visiting scientist in the Bureau of Meteorology Research Center (BMRC) in Melbourne (Australia) in the framework of a collaboration between the BMRC, the Melbourne University and the CESBIO for the analysis of experimental data over the SMOS cal/val sites. Since 2008 , she is head of the Applications Department at isardSAT. Her scientific fields of interest are the application of passive and active microwave remote sensing to hydrology and climate change studies. 